\title{
Chemoanatomical Organization of the Noradrenergic Input From Locus Coeruleus to the Olfactory Bulb of the Adult Rat
}

\author{
JOHN H. MCLEAN, MICHAEL T. SHIPLEY, WILLIAM T. NICKELL, GARY ASTON-JONES, \\ AND CHRISTIAN K.H. REYHER \\ Department of Anatomy and Cell Biology (J.H.M., M.T.S., W.T.N.) and Department of \\ Neurosurgery (M.T.S.), University of Cincinnati College of Medicine, Cincinnati, Ohio \\ 45267-0521; Department of Mental Health Sciences, Hahnemann University, Philadelphia, \\ Pennsylvania 19102 (G.A.-J.); Department of Neurobiology, Max-Planck-Institut fur \\ Biophysikalishe Chemie, D 3400 Gottingen, Federal Republic of Germany (C.K.H.R.)
}

\begin{abstract}
The locus coeruleus contains noradrenergic neurons which project widely throughout the CNS. A major target of locus coeruleus projections in the rat is the olfactory bulb (Shipley et al.: Brain Res. 329:294-299, '85) but the organization of the projections within the bulb has not been systematically examined. In this study, the laminar distribution and densities of locus coeruleus-noradrenergic fibers in the main and accessory olfactory bulbs were determined with anterograde tracing and immunocytochemical techniques.

Following iontophoretic injections of $1 \%$ wheat germ agglutinin-horseradish peroxidase into the locus coeruleus, the densest anterograde label in the accessory olfactory bulb was observed in the external plexiform layer, granule cell layer, and especially in the internal part of the mitral cell layer. Virtually no label was observed in the glomerular layer. In the main olfactory bulb, labelled axons were observed in the granule cell layer, in the internal and external plexiform layers, occasionally in the mitral cell layer, and least often in the glomerular layer.

Noradrenergic fibers in the olfactory bulb were identified by using immunocytochemistry with an antibody to dopamine- $\beta$-hydroxylase. Laminar patterns and densities of noradrenergic innervation were determined with quantitative image analysis. In the accessory olfactory bulb, the densest innervation was in the innermost portion of the mitral cell layer followed by the granule cell layer, the superficial part of the mitral cell layer, and the external plexiform layer. The density of fibers in the glomerular layer was least. The laminar pattern of noradrenergic fiber distribution in the main olfactory bulb was similar to that in accessory olfactory bulb.

The present studies demonstrate that locus coeruleus-noradrenergic fibers terminate preferentially in the internal plexiform, granule cell, and external plexiform layers. This suggests that the major influence of the locus coeruleus input to both the main and accessory the olfactory bulbs is on the predominant neuronal element in those layers, the granule cells. Additional studies are needed to resolve how this input influences specific olfactory bulb circuits.
\end{abstract}

Key words: immunohistochemistry, doparnine-beta-hydroxylase, rodent, wheat germ agglutinin-horseradish peroxidase, olfactory system foundland, Canada AIB 3V6.

Address reprint requests to Michael T. Shipley, Department of Anatomy and Cell Biology, Division of Neurobiology, University of Cincinnati College of Medicine, Cincinnati, OH 45267-0521. 
The locus coeruleus (LC) projects widely throughout the neuraxis and has been implicated in various functions including learning, arousal, sleep, and psychiatric disorders (Jouvet, '67, '69; McCarley and Hobson, '75; Foote et al., '83). Recently, LC has been hypothesized to be particularly important for the detection of sensory stimuli during states of heightened vigilance (Aston-Jones and Bloom, '81; AstonJones, '85). This functional hypothesis is consistent with neuroanatomical data showing that phylogenetically developed sensory areas such as somatosensory and extrastriate visual cortices in primates (Morrison et al., '84) and olfactory bulb in rats (Shipley et al., ' 85 ) receive especially heavy innervation from LC.

In the rat, all LC neurons contain noradrenaline (NE) (Swanson and Hartman, '75; Grzanna and Molliver, '80) and at least $40 \%$ of these neurons project to the olfactory bulb (Shipley et al., '85). The rat, a nocturnal animal, probably relies more upon odor cues than upon other neocortical sensory modalities such as vision. Thus, the preferentially heavy LC innervation of the olfactory bulb is consistent with the idea that LC may be involved in odor vigilance functions in the rat.

In recent years, the patterns and relative densities of LC-NE fibers in various neocortical regions have been elucidated in great detail, particularly in the primate (Morrison et al., '82). It has become evident that NE fibers in the primate neocortex terminate with some laminar specificity. It has further been observed that in many cortical areas there is a degree of complementarity in the innervation of different cortical layers by NE and serotonergic (5-HT) fibers. For example, in the monkey visual cortex NE fibers preferentially innervate layers III, V, and VI whereas 5-HT fibers are relatively sparse in those layers but denser in layer IV (Morrison et al., ' 82 ). This has led to the suggestion that NE and 5-HT systems may provide complementary modulation of cortical functions by acting preferentially on complementary cortical layers (Morrison et al., '82).

We recently demonstrated that there is a striking laminar preferentiality of 5 -HT fibers in the rat olfactory bulb (McLean and Shipley, '87a). Much less is known about the organization of LC-NE fibers in this structure. Previous descriptions of NE fibers in the mammalian olfactory bulb utilized the Falck-Hillarp technique to visualize monoamines (Dahlström et al., '65; Lindvall and Björklund, '74; Fallon and Moore, '78; Shipley et al., '85). However, the olfactory bulb contains a large population of intrinsic dopaminergic neurons that are labelled by the catecholamine fluorescent technique, making it difficult to characterize the specific distribution of NE fibers. In the present study, this difficulty was overcome by immunocytochemistry using antibodies to the prerequisite enzyme for NE, dopamine-betahydroxylase. In addition, the pattern of LC innervation in the bulb was visualized by anterograde tracing methods using physiologically guided injections of wheat germ agglutinin-horseradish peroxidase (WGA-HRP) in LC.

\section{MATERIALS AND METHODS}

Adult (older than 60 postnatal days) male and female Sprague-Dawley rats $(300-350 \mathrm{~g})$ were used in all experiments.

\section{Wheat germ agglutinin-horseradish peroxidase (WGA-HRP) tracing}

WGA-HRP was used to determine the axonal trajectories and termination sites of LC projections to the olfactory bulb. Rats were anaesthetized with chloral hydrate $(400 \mathrm{mg} /$ $\mathrm{kg}$, IP). A glass pipette containing $1 \%$ WGA-HRP (in $0.1 \mathrm{M}$ phosphate-buffered saline) was advanced stereotaxically to the LC. Correct placement of the electrode tip in LC was determined by identification of the characteristic spike waveform and tail-pinch-evoked response of LC neurons recorded via the injection pipette (Aston-Jones et al., '86). When an LC neuron was identified, WGA-HRP was iontophoretically injected ( 7 seconds on/off, $0.5-3 \mu \mathrm{amp}$ ) for $5-20$ minutes.

One or 2 days after injection, the rats were deeply anaesthetized with sodium pentobarbital $(80 \mathrm{mg} / \mathrm{kg})$ and perfused, and the brains were processed as described previously (McLean and Shipley, '87a,b). Frozen sections (40 $\mu \mathrm{m}$ thick) were cut in either the coronal or the sagittal plane and processed for HRP histochemistry (Mesulam, '78) with modifications (Shipley, '82).

\section{Immunohistochemistry}

Rats were perfused with ice-cold saline (2 minutes) followed by ice-cold $4 \%$ formaldehyde freshly prepared from paraformaldehyde in phosphate buffer ( $\mathrm{pH} 7.4,30$ minute perfusion). The brain was then removed from the skull, placed in fixative for 1-2 hours, and left overnight in $20 \%$ sucrose in phosphate buffer at $4^{\circ} \mathrm{C}$.

Thirty-micron-thick frozen coronal or parasagittal sections of the brain were collected in cold phosphate buffer and then transferred into the primary antibody solution containing $0.1 \%$ Triton $\mathrm{X}-100,2 \%$ normal goat serum, and $0.02 \%$ sodium azide in phosphate-buffered saline. The antibody to dopamine-beta-hydroxylase $(\mathrm{DBH})$ was obtained from Eugene Tech., Inc.; its specificity has been established by the company by using Western blot and immunocytochemistry. In addition, we routinely compared the patterns of staining in other brain regions of our material to those obtained in previous studies of the distribution of NE fibers in the rat. Optimum staining of olfactory bulb tissue was obtained with a 1:600 dilution of the primary antisera.

\section{Image analysis and quantitation}

Video images of DBH-immunoreactive (IR) fibers and LC axons anterogradely labelled with WGA-HRP were contrast enhanced and charted by using reconstruction sof tware developed in this laboratory (McLean and Shipley, '87a,b) for a video-based image analysis computer system (Magiscan 2A, Joyce Loebl) interfaced with either a Leitz Orthoplan or a Nikon Microphot FX microscope. Fibers were reconstructed in both the coronal and sagittal planes while fiber density measurements were made in the coronal plane only.

The density of fibers was estimated by measuring $\mathrm{DBH}$ IR fibers in one section from each animal. In each section the field that was examined was $350,000-460,000 \mu \mathrm{m}^{2}$. The mean density of fibers was obtained from the olfactory bulbs of four rats.

\section{RESULTS Anterograde WGA-HRP label}

Iontophoretic injections of WGA-HRP were usually confined to the boundaries of the LC. Anterograde axonal and terminal label were observed leading to the olfactory bulb via the medial forebrain bundle and medial olfactory tracts as described previously (Dahlström et al., '65; Lindvall and Björklund, '74; Fallon and Moore, '78). Anterograde label 


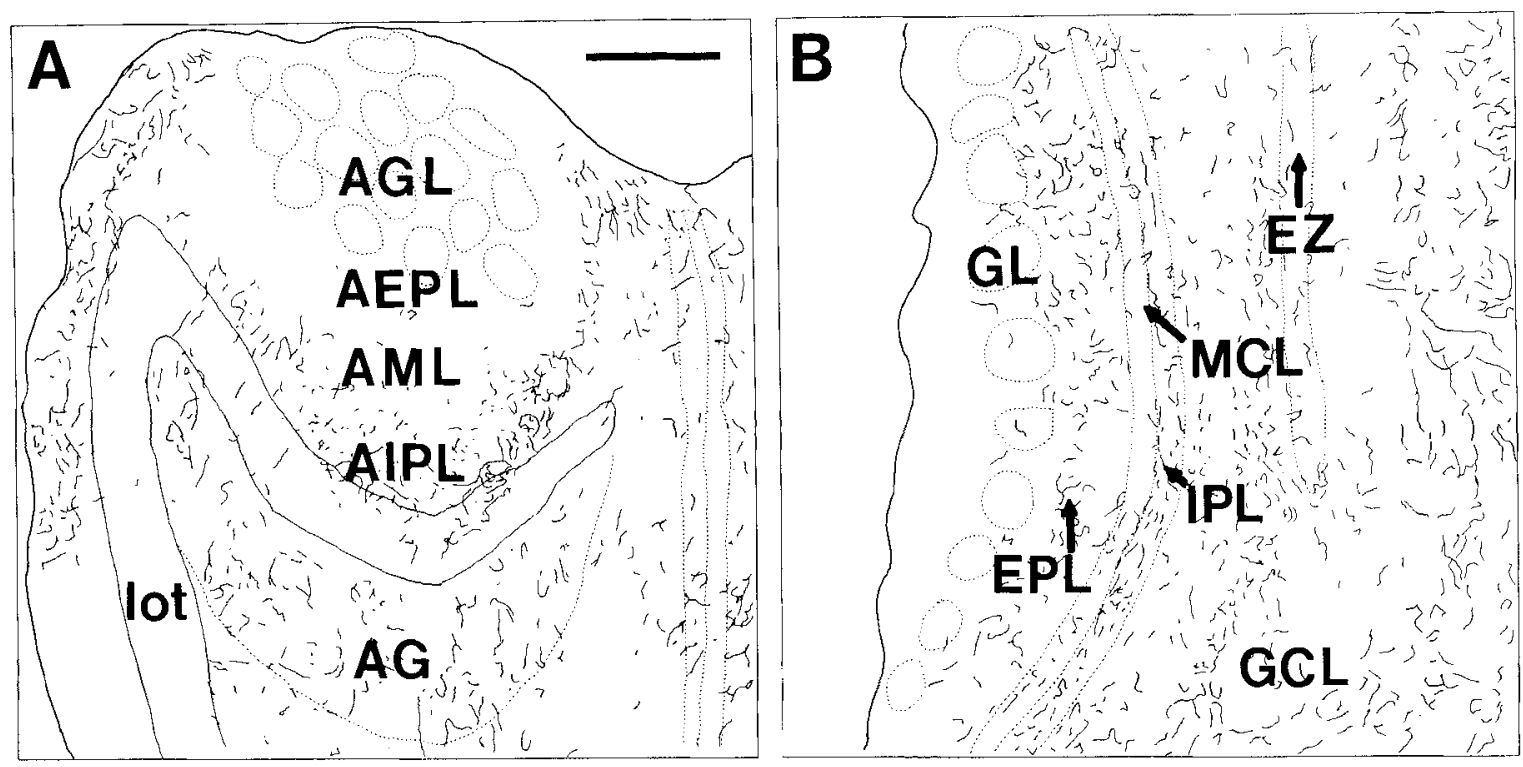

Fig. 1. Computer reconstruction of anterograde label in the accessory (A) and main (B) olfactory bulbs following injection of WGA-HRP into the locus coeruleus. Bar, $200 \mu \mathrm{m}$.

was observed in both the accessory (AOB) and main (MOB) olfactory bulbs.

$\boldsymbol{A O B}$. The $\mathrm{AOB}$ is a small structure located at the dorsomedial-caudal aspect of the main olfactory bulb (MOB). It receives inputs from first-order olfactory neurons in the vomeronasal organ which parallel the inputs to MOB from the main olfactory epithelium. AOB is composed of several distinct layers including the glomerular, mitral cell, and granule cell layers (Fig. 2A). The external and internal plexiform layers are less distinct than their counterparts in the MOB (Fig. 3A), and there is lack of agreement in defining an internal plexiform layer in $\mathrm{AOB}$. Based on the distribution of the LC-NE input and cytoarchitectonic analysis presented below we will designate the region between the relatively condensed band of mitral cells and the lateral olfactory tract as the internal plexiform layer of the AOB (Fig. 2A).

WGA-HRP-labelled fibers from LC were distributed mainly in the internal plexiform layer, external plexiform layer, granule cell layer, and mitral cell layer of the AOB (Fig. 1A). Virtually no label was visualized in the glomerular layer. Heavy anterograde label was observed in the external and lateral subdivisions of the anterior olfactory nucleus which are adjacent to the AOB and caudal MOB. The anterior olfactory nucleus, which appears to receive an even denser input from the LC than does the AOB, will be addressed in a further communication.

MOB. In the MOB, numerous labelled fibers were present in the granule cell and internal plexiform layers while in the external plexiform layer, individual fibers as well as punctate label were observed (Fig. 1B). Only sparse label was present in the glomerular and olfactory nerve layers. In the coronal plane, most of the fibers had a circumferential orientation running parallel to the surface of the MOB. In the parasagittal plane, the majority of inframitral fibers appeared to course longitudinally. Thus, in the granule cell and internal plexiform layers few fibers are radially oriented. Some fibers coursed radially through the mitral cell layer into the external plexiform layer; a few fibers reached, but rarely entered, the glomerular layer. These fibers were most often adjacent to the soma of periglomerular neurons and usually did not penetrate the interior of a glomerulus.

It was usually difficult to determine if the punctate label observed in the external plexiform layer represented axonal label or was an artifact of the tetramethyl benzidine (TMB) method. This layer is normally very active metabolically and probably contains endogenous peroxidases which react nonspecifically with the chromogen. Most of the anterograde label in AOB and MOB from LC remained ipsilateral to the injected side. The external plexiform layer of the contralateral olfactory bulb often had punctate label nearly as

\section{Abbreviations}

AEPL AG AGL

AIPL

AML

$\mathrm{AOB}$

AOE

AOL

AON

$\mathrm{DBH}$

EPL

EZ

5 -H'T

GCL

GL

IPL

IR

LC

lot

MCL

$\mathrm{MOB}$

WGA-HRP external plexiform layer of accessory olfactory bulb granule cell layer of accessory olfactory bulb glomerular layer of accessory olfactory bulb internal plexiform Jayer of accessory olfactory bulb mitral cell layer of accessory olfactory bulb accessory olfactory bulb

external subdivision of anterior olfactory nucleus lateral subdivision of anterior olfactory nucleus anterior olfactory nucleus dopamine-beta-hydroxylase

external plexiform layer of main olfactory bulb subependymal zone serotonergic, serotonin granule cell layer of main olfactory bulb glomerular layer of main olfactory bulb internal plexiform layer of main olfactory bulb immunoreactive

locus coeruleus

lateral olfactory tract

mitral cell layer of main olfactory bulb main olfactory bulb

noradrenergic, noradrenaline

wheat germ agglutinin-horseradish peroxidase 

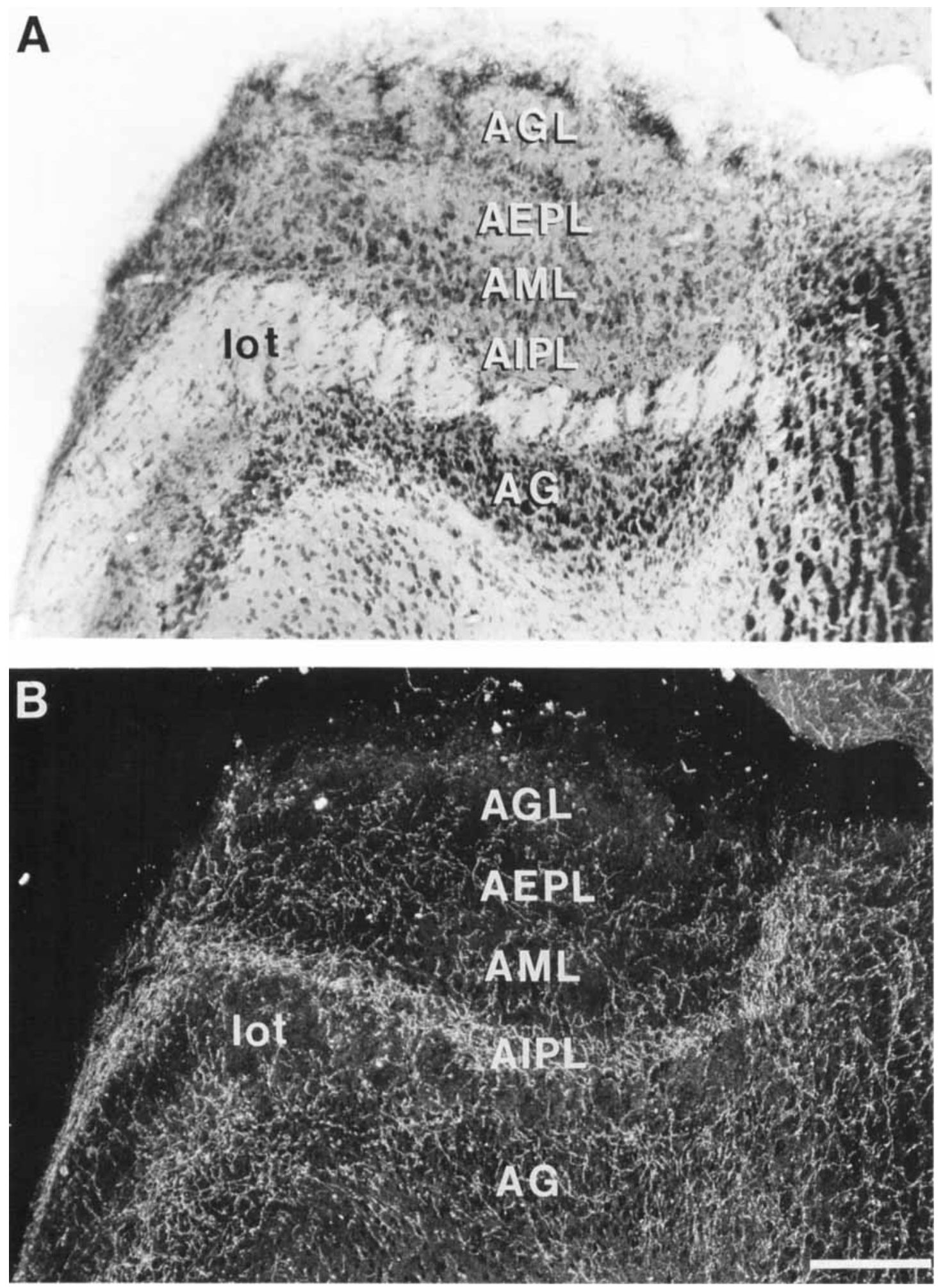

Fig. 2. A: Brightfield photomicrograph of a coronal section through AOB stained with cresyl violet. B: The same section under darkfield illumination shows the distribution of DBH-IR fibers in the different layers. Bar, $100 \mu \mathrm{m}$. 

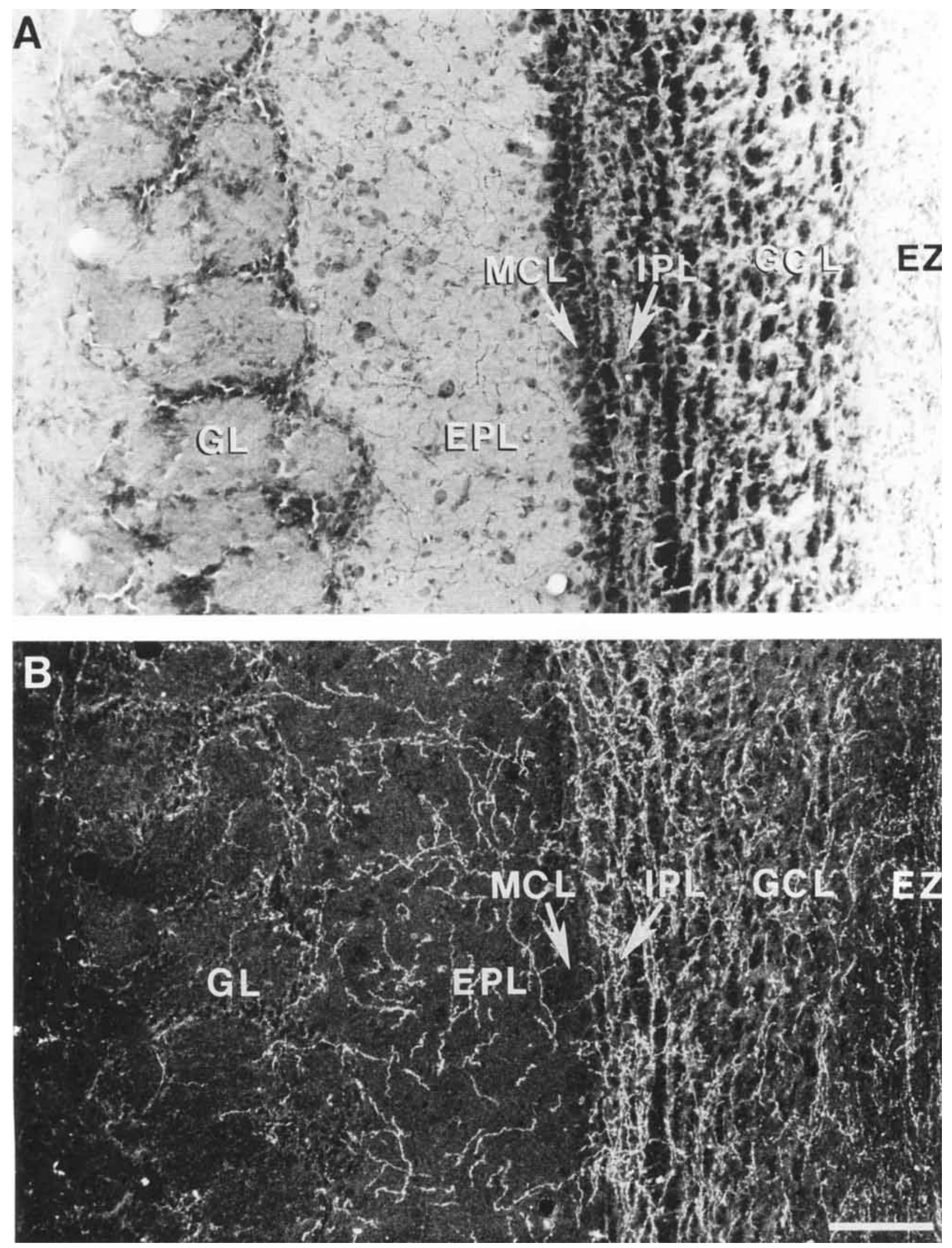

Fig. 3. A: Brightfield photomicrograph of a Nissl-stained coronal section through MOB. B: The same section under darkfield illumination shows the distribution of DBH-IR fibers in the MOB. Bar, $100 \mu \mathrm{m}$. 


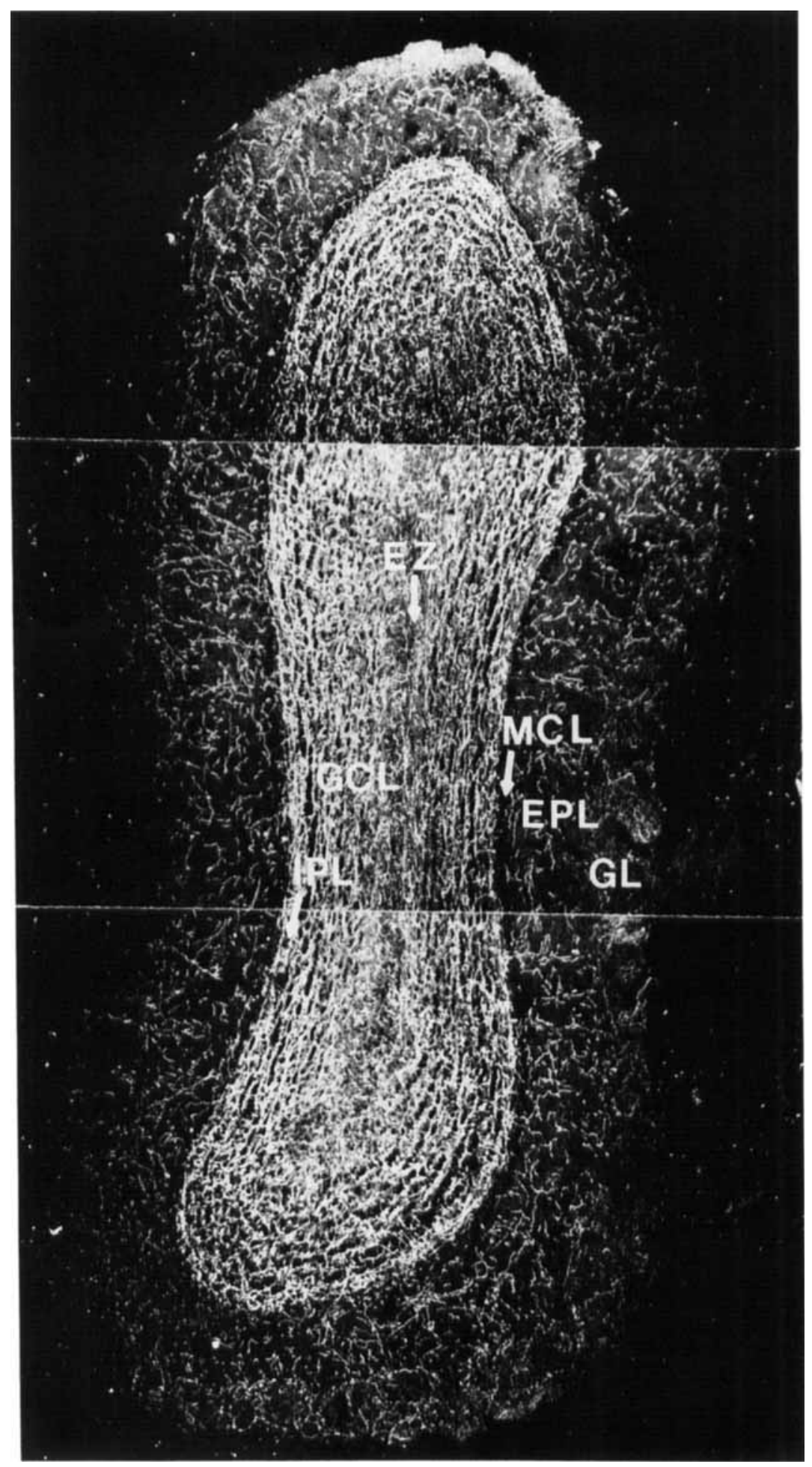

Fig. 4. Low-magnification darkfield photomontage of $\mathrm{MOB}$ showing the heterogeneous distribution of DBH-IR fibers. Coronal section. Bar, $300 \mu \mathrm{m}$. 
TABLE 1. Density of DBH-IR Fibers in Different Layers of AOB and MOB

\begin{tabular}{lccc}
\hline & & \multicolumn{2}{c}{ Density $\left(\mu \mathrm{m} / 100 \mu \mathrm{m}^{2}\right)$} \\
\cline { 3 - 4 } & $\mathrm{N}$ & $\mathrm{AOB}$ & $\mathrm{MOB}$ \\
\hline Glomerular layer & 4 & $1.7 \pm 0.5$ & $0.7 \pm 0.3$ \\
External plexiform layer & 4 & $2.8 \pm 1.3$ & $3.3 \pm 1.3$ \\
Mitral cell layer & 4 & $4.0 \pm 0.6$ & $3.7 \pm 1.4$ \\
Internal plexiform layer & 4 & $8.2 \pm 0.6$ & $7.3 \pm 0.7$ \\
Granule cell layer & 4 & $4.2 \pm 0.5$ & $5.2 \pm 0.7$ \\
Subependymal zone & 4 & - & $4.7 \pm 1.1$ \\
\hline
\end{tabular}

DBH-IR, dopamine-beta-hydroxylase-immunoreactive; $A O B$ and $M O B$, accessory and main olfactory bulbs.

dense as that observed in the ipsilateral external plexiform layer; however, because no other layers in the contralateral bulb had significant anterograde label, we assume that most of the punctate label in the external plexiform layer is an artifact of the HRP histochemistry method. Artifactual punctate reaction product in the external plexiform layer of MOB has frequently been observed in this laboratory in studies that did not involve anterograde transport to MOB. This artifact can be reduced or eliminated by prolonged fixation or modifications of the HRP reaction protocol, but unfortunately, these maneuvers also reduce the bona fide anterograde labelling. Thus, it was necessary to use the distribution of immunoreactive labelling of noradrenergic fibers to further assess the distribution of LC fibers in the external plexiform layer.

\section{DBH-IR label}

$A O B$. Immunoreactive fibers were located in the granule cell (Fig. 2B), internal plexiform mitral cell, external plexiform, and glomerular layers as well as in the lateral olfactory tract. The fibers in the granule and mitral cell layers had no strongly preferential orientation. Fibers in the external plexiform layer had a mainly radial orientation. DBH-IR fibers coursed through the lateral olfactory tract but only where granule cells were also present.

Laminar fiber densities were determined by video image analysis. DBH-IR fibers were densest in the internal plexiform layer followed by the mitral cell layer, granule cell layer, and the external plexiform layer (Table 1). Some of the fibers that ran through the external plexiform layer reached the region of periglomerular cells but only rarely penetrated to the core of the glomeruli (Figs. 3B, 5A). The glomerular layer of $\mathrm{AOB}$ only rarely contained immunoreactive fibers (Table 1).

MOB. The thin internal plexiform layer was the most heavily innervated in the MOB. Most of the DBH-IR fibers in that layer were oriented parallel to the surface of MOB (Figs. 3B, 4, 5). The next most heavily innervated layer was the granule cell layer, and third was the subependymal zone. Most fibers in the external plexiform layer are oriented radially, although in the deep third of the layer many fibers are oriented parallel to the bulb surface. The mitral cell layer receives NE fibers but to a lesser extent than the immediately subjacent internal plexiform layer. Many of the fibers associated with the mitral cell layer appear to be passing through to the external plexiform layer. As in the $\mathrm{AOB}$, the glomerular layer of the $\mathrm{MOB}$ is least densely innervated by DBH-IR fibers and the fibers were most often associated with periglomerular cells forming the wall of the glomeruli.

Fiber density measurements were taken from the midrostrocaudal third of the bulb in sections cut in the coronal plane. The density of fibers in each layer (from highest to lowest density) was similar to the density of fibers in the homologous layer of $\mathrm{AOB}$. Therefore, the densest innervation was in the internal plexiform layer and the least dense in the glomerular layer (Table 1).

Axon morphology. The morphology of DBH-IR axons was similar in all layers in the $\mathrm{MOB}$ and $\mathrm{AOB}$. The axons were thin $(0.25 \mu \mathrm{m})$, approaching the limits of light microscopic resolution. The varicosities were larger (approximately $0.5-1.5 \mu \mathrm{m}$ ) in all layers except for the glomerular layer, where the varicosities were only slightly larger than the axon diameter but were detectable because they stained more intensely than the rest of the axon. Intervaricosity distances ranged from 1 to $5 \mu \mathrm{m}$ in all layers of the olfactory bulb.

\section{DISCUSSION Distribution of NE fibers}

We previously reported that at least $40 \%$ of LC neurons project to the rat olfactory bulb (Shipley et al., '85). The present study demonstrates that the $\mathrm{NE}$ innervation from the LC to the olfactory bulb is quite heavy, consistent with the high percentage of LC neurons retrogradely labelled by injections of WGA-HRP in the olfactory bulb. In addition, the present findings demonstrate that there is a striking degree of laminar specificity in the organization of NE fibers to both the main and accessory olfactory bulbs: NE-LC fibers project substantially to the granule cell layer, subependymal zone, and internal plexiform layers. Fewer fibers are found in the external plexiform layer and only rarely are fibers found in the glomerular layer. Thus, the NE innervation of both the MOB and $A O B$ is densest in the inframitral cell layers.

Overall, NE innervation of the $\mathrm{MOB}$ and $\mathrm{AOB}$ is similar. Slight differences in the NE innervation of the two structures may be explained in part by differences in their cytoarchitecture. For example, the mitral cell layer is different in MOB and $\mathrm{AOB}$; in MOB the output cells form essentially a monolayer while in the AOB the cells are grouped in a multilayer that makes the external and internal plexiform layers less distinct (Switzer et al., '85). The deep part of the mitral cell layer in AOB may, thus, be equivalent to the internal plexiform layer since many of the same neuronal components (axons of mitral cells, dendrites of granule cells) are located in both of the regions and they both receive a very dense $\mathrm{NE}$ innervation. Therefore, based in part on the NE innervation pattern revealed here, we suggest that in $A O B$ the deepest part of the mitral cell layer might best be considered a mixture of mitral cell layer and internal plexiform layer. The impression from the orientation of these fibers is that many of the fibers may be passing through to the main olfactory bulb (Fig. 5A).

The present report is at variance with one of our previous observations (Shipley et al., '85). Earlier, we used the glyoxylic acid method to visualize catecholamine fibers in the bulb. The patterns of catecholamine fluorescent fibers were similar to those seen with $\mathrm{DBH}$ with one notable exception. In the histofluorescence material a dense fiber plexus was observed in the glomerular layer. We interpreted those results to suggest that NE fibers ramified in the glomeruli. We pointed out that this conclusion was tentative because the glomerular catecholaminergic fiber staining might be attributable to the processes of periglomerular dopaminergic neurons previously reported by others. However, be- 


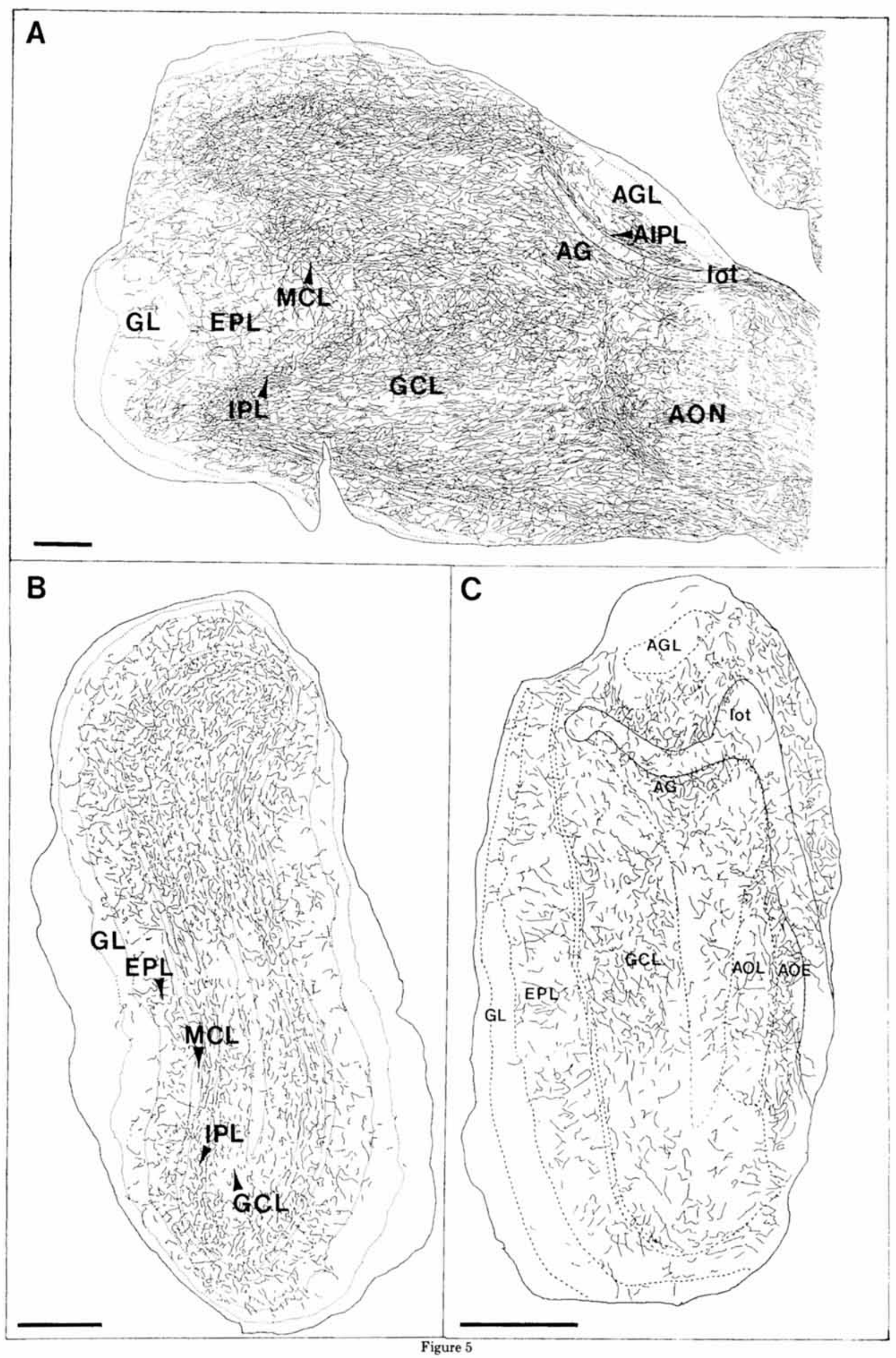


cause our glyoxylic acid material did not stain periglomerular dopamine cell bodies, we suggested that the intraglomerular fiber staining might be associated with NE$\mathrm{LC}$ axons. The present results indicate that this surmise was incorrect. Neither the DBH-IR staining nor the LC anterograde labelling demonstrate anything more than sparse NE innervation of a few glomeruli. The lack of NE innervation of the glomerular layer is in stark contrast to the rich 5-HT innervation of that layer (McLean and Shipley, '87a).

The densest NE innervation of the olfactory bulb is to the internal plexiform layer. This is a cell-poor region which contains axons of mitral cells and the dendrites of granule cells and other, less frequent non-granule inframitral interneurons. Thus, these neuronal elements could form postsynaptic targets for the NE axons.

The granule cell layer of both $\mathrm{AOB}$ and MOB is the second most densely innervated target of NE fibers. Since granule cells are the predominant neural element in this layer and their dendrites are one of the most common neural elements in the internal plexiform layer, it is reasonable to suggest that the granule cells are the most likely target of NE fibers. It should be noted, however, that the inframitral layers also contain many presynaptic fibers and terminals from ipsi- and contralateral association projections (Luskin and Price, '83); NE fibers could be presynaptic to these centrifugal fibers or to recurrent collaterals of tufted or mitral cells.

The external plexiform layer also has appreciable NE fibers. Since this layer contains mainly dendrites of mitral cells and granule cells as well as centrifugal fibers, there are several candidate targets of NE fibers in this layer as well.

The NE input to the subependymal zone of MOB is very dense. This layer is a cell-poor region in the adult olfactory bulb and does not contain many centrifugal fibers. The most likely targets of NE fibers in the layer, therefore, are the basal dendrites of granule cells, although conceivably the LC axons may pass through this layer to reach other layers of the bulb.

In summary, NE fibers preferentially innervate the inframitral layers and to a lesser degree, the external plexiform layer; these layers contain several candidate postsynaptic target elements including mitral cells, centrifugal afferent fibers, and granule cells. However, the neural element common to all these layers is the granule cell. An earlier electron microscopic study using ${ }^{3} \mathrm{H}$-noradrenaline uptake (Halasz et al., '78) also suggested that NE fibers contact dendrites of granule cells, but electron microscopic studies using more specific antibody labelling methods are needed to confirm this. Neurophysiological studies to be reviewed below also suggest that $\mathrm{NE}$ inputs preferentially target granule cells.

\section{Physiological actions of noradrenaline in the olfactory bulb}

There is lack of agreement about the actions of NE on neurons in the olfactory bulb. On the one hand, Salmoiraghi et al. ('64) reported that iontophoretic application of NE caused a suppression of the spontaneous activity of "olfactory neurons." Although the neuron types recorded were not identified, it is probably likely that the authors were recording mitral and tufted cells as most deep interneurons in the bulb are not spontaneously active. McLennan ('71) specifically identified mitral cells by antidromic activation from the lateral olfactory tract and reported that iontophoretic application of NE caused a suppression of mitral cell firing. The McLennan study went on to show that NE suppression of mitral cells was eliminated by coadministration of bicuculine-a specific antagonist of $\mathrm{GABA}_{\mathrm{A}}$ receptors. In the olfactory bulb, the granule cells are GABAergic (Ribak, '77) and exert a potent inhibitory action on mitral cells (Jahr and Nicoll, '82) presumably by dendrodendritic contacts with mitral cells (Shepherd, '72). McLennan concluded that NE caused suppression of mitral cell firing by activating GABAergic granule cells. More recently, Jahr and Nicoll ('82), using the turtle olfactory bulb slice, also concluded that NE acts on GABAergic granule cells, but unlike the previous studies of Salmoiraghi et al. ('64) and McLennan ('71), Jahr and Nicoll concluded that NE inhibited the release of GABA, resulting in an increased mitral cell firing. The reasons for these contradictory results are unclear. The Salmoiraghi et al. ('64) and McLennan ('71) experiments were done in the rat whereas Jahr and Nicoll's were in the turtle, so a species difference is certainly possible. However, there are no anatomical data suggesting that there are fundamental differences in the rat and turtle olfactory bulb, although there might be a difference in noradrenergic postsynaptic receptors between the species. Another difference among the studies was that Salmoiraghi et al. ('64) and McLennan ('71) applied NE locally by iontophoresis in an in vivo preparation, whereas, Jahr and Nicoll's studies used an in vitro preparation in which the slices were bathed in NE (micromolar) for 8-24 minutes. Whether prolonged incubation in micromolar concentrations of NE is comparable to the conditions of functional synaptic release of NE is unclear.

Whatever the eventual resolution of the contradictory physiological actions of NE, the above-cited investigations agree that NE acts on mitral/tufted cell firing through GABAergic interneurons. This is entirely consistent with the tract-tracing and immunocytochemical findings of the present report and supports the hypothesis that LC-NE fibers may be primarily targeted on olfactory bulb granule cells.

Whether NE causes increased release of GABA with resulting suppression of mitral cell firing, as suggested by Salmoiraghi et al. ('64) and McLennan ('71), or causes a reduction of GABA release with an increase of mitral cell fibers, as suggested by Jahr and Nicoll ('82), will have to be resolved by additional physiological studies. This question is of considerable interest for understanding the functional significance of the LC. Aston-Jones and Bloom ('81) have hypothesized that LC plays a key role in functions involving heightened vigilance. Consistent with this concept are studies showing that NE preferentially suppresses the spontaneous firing of sensory cortical neurons without altering their response to sensory evoked stimulation (Waterhouse et al., '86). These results have been interpreted to mean that NE acts to increase the "signal-to-noise" ratio in cortical neurons. Such a function would be consistent with improved signal detection, i.e., improved vigilance. The results of Salmoiraghi et al. ('64) and McLennan ('71), indicating that NE causes increased release of GABA with a resultant decrease in mitral cell spontaneous discharge, and the pres- 
ent anatomical data indicating that LC neurons may be preferentially targeted on GABAergic granule cells would provide an interesting anatomical substrate for LC-NE synapses to effect a signal-to-noise reduction in principal neurons. In the olfactory bulb, the mitral cell (principal neuron) has two classes of dendrites. The lateral dendrites ramify in the external plexiform layer where they are densely contacted by granule cell (GABAergic) inhibitory synapses; these synapses are complemented by adjacent excitatory reciprocal synapses from mitral to granule cells (Rall et al., '66; Shepherd, '72; Jackowiski et al., '78). The apical dendrite of the mitral cell extends, without branching or spines, through the external plexiform layer to the glomerular layer where it ramifies extensively in a single glomerulus and receives contacts from primary olfactory nerve fibers and periglomerular interneurons. It is this apical branch of the mitral cell dendrite which conducts the sensory throughput. If LC-NE synapses cause the release of GABA from granule cells this would tend to suppress activity in the lateral dendrites of the mitral cell which might serve to reduce spontaneous firing of this cell. However, because the apical dendrite of the mitral cell does not appear to receive significant granule cell contacts, the conduction of signals from olfactory nerve synapses on the glomerular branches of the mitral cell's apical dendrite would probably not be appreciably influenced by the action of NE on granule cells. The present study demonstrated that LC-NE fibers largely avoid the glomerular layer; thus, LC activation would not engage the periglomerular GABAergic neurons that act on the apical dendrites of mitral cells. The net effect of this anatomical arrangement could be to reduce spontaneous mitral cell firing without reducing sensory throughput conducted by mitral cell apical dendrites. Though admittedly speculative, this scheme is amenable to direct experimental test: Stimulation of LC or local administration of NE should decrease spontaneous mitral firing (Salmoiraghi et al., '64; McLennan, '71) but not reduce mitral cell responsiveness to odor stimuli or shocks to the olfactory nerve. If this hypothesis is correct, it might suggest that, in general, LC neurons preferentially target inhibitory interneurons in other sensory cortical areas and function to increase the signal-tonoise ratio in sensory processing by a similar mechanism to that hypothesized for the olfactory bulb.

\section{Role of NE in olfactory behavior}

Behavioral experiments have implicated NE in at least two functions related to recognition of odors of other animals. First, the formation of a selective bond between ewes and their offspring is lost when NE input to the olfactory bulb is eliminated (Pissonier et al., '85). Second, a female mouse will spontaneously abort if presented with a male odor other than that of its mate (Bruce, '60). This pregnancy block can be prevented by depleting the NE input to the olfactory bulb, specifically the $\mathrm{AOB}$, prior to mating (Keverne and de la Riva, '82; Rosser and Keverne, '85). The pregnancy block effect is particularly interesting in view of the idea that LC functions to improve vigilance and the detection of novel stimuli. Other studies (Gray et al., '86; Sullivan and Leon, '87) indicate that NE may be involved in odor learning and/or imprinting which may require a signal-tonoise enhancement mechanism.

\section{5-HT and NE complementarity and overlap}

The pattern of NE innervation of the olfactory bulb is remarkably complementary to the 5-HT innervation of the same structure. Serotonergic (5-HT) fibers most densely innervate the glomerular layer of MOB (McLean and Shipley, '87a) while NE fibers largely avoid that layer. In contrast, the layers most heavily innervated by NE fibers are the internal plexiform and granule cell layers. Since NE and 5-HT fibers appear to have different postsymaptic targets in the main olfactory bulb, their functions may be different and complementary. Thus, it is conceivable that these two monoaminergic systems have very different net effects on olfactory neural processing.

In other areas of the brain, it appears that NE action on neocortical neurons is complementary to the action of 5-HT. For example, in the somatosensory cortex, 5 -HT acts to suppress sensory evoked unit firing relative to background firing (Waterhouse et al., '86). However, to date there have been no studies in which the specific neuronal types responding to the actions of NE and 5-HT have been identified. Thus, it is difficult to know if NE and 5-HT produce different effects via different receptors and channels on the same neuron or whether they act on different neuronal targets. Additional physiological studies taking into account the anatomical specificity of NE and 5-HT terminals and postsynaptic target cells are needed to determine the roles of these monoamines in cortical functions. The relative simplicity of the olfactory bulb and the laminar complementarity of 5-HT and NE inputs may allow such issues to be more directly addressed in the bulb than in the more complicated neocortex.

\section{ACKNOWLEDGMENTS}

The authors wish to thank Dr. B. Frydel, Y. Tsai, and M. Springston for technical assistance and S. Harding for typing the manuscript. Mr. J. Luna wrote many of the programs used for image analysis. This work was supported by grants to M.T.S. (NINCDS 23348-01, DAMD 17-86-C-6005, NIH RO1 NS 22053) and G.A.-J. and M.T.S. (NIH RO1 NS 24698).

\section{LITERATURE CITED}

Aston-Jones, G. (1985) Behavioral functions of locus coeruleus derived from cellular attributes. Physiol. Psychol. 13:118-126.

Aston-Jones, G., and F.E. Bloom (1981) Activity of norepinephrine-containing locus coeruleus neurons in behaving rats anticipates fluctuations in the sleep-waking cycle. J. Neurosci. 1:876-886.

Aston-Jones, G., M. Ennis, V. Pieribone, W.T. Nickell, and M.T. Shipley (1986) The brain nucleus coeruleus: Restricted afferent control of a broad efferent network. Science 234:734-737.

Bruce, H. (1960) A block to pregnancy in the mouse caused by the proximity of strange males. J. Reprod. Fertil. 1:96-103.

Dahlström, A., K. Fuxe, L. Olson, and U. Ungerstedt (1965) On the distribution and possible function of monoamine nerve terminals in the olfactory bulb of the rabbit. Life Sci. 4:2071-2074.

Fallon, J.H., and R.Y. Moore (1978) Catecholamine innervation of the basal forebrain. II. Olfactory bulb, anterior olfactory nuclei, olfactory tubercle and piriform cortex. J. Comp. Neurol, 180:533-544.

Foote, S.L., F.E. Bloom, and G. Aston-Jones (1983) Nucleus locus coeruleus: New evidence of anatomical and physiological specificity. Physiol. Rev. 63:844-914.

Gray, C.M., W.J. Freeman, and J.E. Skinner (1986) Chemical dependencies of learning in the rabbit olfactory bulb: Acquisition of the transient spatial pattern change depends on norepinephrine. Behav. Neurosci. 100:585-596.

Grzanna, R., and M.E. Molliver (1980) The locus coeruleus in the rat: An immunohistochemical delineation. Neuroscience 5:21-40.

Halasz, N., A. Ljundahl, and T. Hökfelt (1978) Transmitter histochemistry of the rat olfactory bulb. II. Fluorescence histochemistry, autoradiographic and electron microscopic localization of monoamines. Brain Res. 154:253- 
271.

Jackowski, A., J.G. Parnavelas, and A.R. Lieberman (1978) The reciprocal synapse in the external plexiform layer of the mammalian olfactory bulb. Brain Res. 195:17-28.

Jahr, C.E., and R.A. Nicoll (1982) Noradrenergic modulation of dendrodendritic inhibition of the olfactory bulb. Nature (Lond.) 297:227-228.

Jouvet, M. (1967) Neurophysiology of states of sleep. Physiol. Rev. 47:117177.

Jouvet, M. (1969) Biogenic amines and the states of sleep. Science 163:3241.

Keverne, E.B., and C. de la Riva (1982) Pheromones in mice: Reciprocal interaction between the nose and brain. Nature (Lond.)296:148-150.

Lindvall, O., and A. Björklund (1974) The organization of the ascending catecholamine neuron systems in the rat brain. Acta Physiol. Scand. [Suppl.]412:1-48.

Luskin, M.B., and J.L. Price (1983) The topographic organization of association fibers of the olfactory system in the rat, including centrifugal fibers to the olfactory bulb. J. Comp. Neurol. 216:264-291.

McCarley, R.W., and J.A. Hobson (1975) Neuronal excitability modulation over the sleep cycle: A structural and mathematical model. Science 189:58-60.

McLean, J.H., and M.T. Shipley (1987a) Serotonergic afferents to the rat olfactory bulb: I. Origins and laminar specificity of serotonergic inputs in the adult rat. J. Neurosci. 7:3016-3028.

McLean, J.H., and M.T. Shipley (1987b) Serotonergic afferents to the rat olfactory bulb: II. Changes in fiber distribution during development. J. Neurosci. 7:3029-3039.

McLennan, H. (1971) The pharmacology of inhibition of mitral cells in the olfactory bulb. Brain Res. 29:177-184.

Mesulam, M.-M. (1978) Tetramethyl benzidine for horseradish peroxidase histochemistry: A noncarcinogenic blue reaction-product with superio sensitivity to visualizing neural afferents and efferents. J. Histochem. Cytochem. 26:106-117.

Morrison, J.H., S.L. Foote, and F.E. Bloom (1984) Regional, laminar, and functional characteristics of noradrenaline and serotonin innervation patterns in monkey cortex. In L. Descarries, T.R. Reader, and H.H. Jasper (eds): Monoamine Innervation of Cerebral Cortex. New York: Alan R. Liss, Inc., pp. 61-75.

Morrison, J.H., S.L. Foote, M.E. Molliver, F.E. Bloom, and H.G.W. Lidov (1982) Noradrenergic and serotonergic fibers innervate complementary layers in monkey primary visual cortex: An immunohistochemical study. Proc. Natl. Acad. Sci. USA 79:2401-2405.

Pissonier, D., J.C. Thiery, C. Fabre-Nys, P. Poindron, and E.B. Keverne (1985) The importance of olfactory bulb noradrenalin for maternal recognition in sheep. Physiol. Behav. 35:361-363.

Rall, W., G.M. Shepherd, T.S. Reese, and M.W. Brightman (1966) Dendrodendritic synaptic pathway for inhibition in the olfactory bulb. Exp. Neurol. 14:44-56.

Ribak, C.E. (1977) The GABAergic neurons of the olfactory bulb in the rat. In J.A. Ferrendelli and G. Guritch (eds): Society for Neuroscience Symposia. III. Aspects of Behavioral Neurobiology. Bethesda: Soc. for Neurosci., pp. 189-203.

Rosser, A.E., and E.B. Keverne (1985) The importance of central noradrenergic neurones in the formation of an olfactory memory in the prevention of pregnancy block. Neuroscience 15:1141-1147.

Salmoiraghi, G.C., F.E. Bloom, and E. Costa (1964) Adrenergic mechanisms in rabbit olfactory bulb. Am. J. Physiol. 207:1417-1424.

Shepherd, G.M. (1972) Synaptic organization of the mammalian olfactory bulb. Physiol. Rev. 52:864-917.

Shipley, M.T. (1982) Insular cortex projections to the nucleus solitarius and brainstem visceromotor regions in the mouse. Brain Res. Bull. 8:139148.

Shipley, M.T., F.J. Halloran, and J. de la Torre (1985) Surprisingly rich projection from locus coeruleus to the olfactory bulb in the rat. Brain Res. 329:294-299.

Sullivan, R., and M. Leon (1987) NE modulation of one-trial olfactory conditioning and olfactory bulb neural responding to an attractive odor. Chem. Senses 12:702-703.

Swanson, L.W., and B.K. Hartman (1975) The central adrenergic system. An immunofluorescence study of the location of cell bodies and their efferent connections in the rat utilizing dopamine-B-hydroxylase as a marker. J. Comp. Neurol. 163:467-506.

Switzer, R.C., J. de Olmos, and L. Heimer (1985) The olfactory system. In G. Paxinos (ed): The Rat Nervous System, Vol. I. Forebrain and Midbrain. Australia: Academic Press, pp. 1-36.

Waterhouse, B.D., H.C. Moises, and D.J. Woodward (1986) Interaction of serotonin with somatosensory cortical neuronal responses to afferent inputs and putative neurotransmitters. Brain Res. Bull. 17:507-518. 